\title{
JMR Rapid Publication Communications
}

Since its inception, the Journal of Materials Research has encouraged short, particularly topical, contributions designated as Communications. Such contributions are presently limited to four published pages. Commencing with this announcement, we will institute new procedures designed to assure more rapid publication of $J M R$ Communications. Following are the revised procedures and guidelines:

- The Communications editor will be Patrick K. Gallagher.

- New, particularly topical results may be designated Communications provided their total length is four or less published pages. (A typed double-spaced $81 / 2^{\prime \prime} \times 11^{\prime \prime}$ equivalent is approximately 10 pages.)

- Manuscripts should be mailed to the $J M R$ Editorial Office, Materials Research Society, 9800 McKnight Road, Pittsburgh, PA 15237, and clearly designated Communications. Authors must include a cover letter which includes mailing address, phone and fax numbers (and e-mail address if available). Also, a copyright and index form should be included. A copy of these can be obtained from the back of $J M R$.

- All refereeing and responses will be handled by e-mail and/or fax.

- To expedite refereeing, authors should suggest three or four qualified referees for each Communication. JMR may choose from these referees or may appoint other referees depending on circumstances.

- JMR's goal is a four-week or less review turnaround time for Communications.

We hope that these new procedures will provide the materials community with a rapid outlet for high quality rapid transmission of exciting new results.

ROBERT A. LAUDISE

Editor-in-Chief

PATRICK K. GALLAGHER

Communications Editor

\section{Parental Volunteer Introduces Materials Science to First Graders}

When my son Michael's first grade teacher asked for parental volunteers in the classroom, I offered to do a science demonstration introducing materials science. She was skeptical but humored me by agreeing. I decided that in order to grab the children's attention, and keep it, I would involve them in hands-on experiments.

In my introduction to the class of about 25 students, I explained that I was a teacher and scientist who worked in the materials engineering department in a university and that I and my colleagues did research on various types of materials. Our goals were to design and produce new materials and improve existing ones. Next, I told the students that the various materials could be divided into three main types: metals, polymers, and ceramics. In addition, some materials are made up of a combination of these (composites). I explained that the different types of materials had different properties. Metals are generally strong and tough (do not break easily), ceramics are hard and brittle, and plastics are often fairly soft and flexible. I showed some examples: a plastic bag and elastic band for polymers, a steel hammer for metals, and a coffee mug and plate for ceramics. I then asked the students to point out examples in their classroom. I was somewhat surprised at their enthusiasm, as virtually every hand in the room went up (it would be nice to have about a tenth of that enthusiasm in my university classes). I chose seven or eight students; the ones not chosen were visibly disappointed. I reassured them that I would try to involve everyone through the course of the demonstrations and experiments. The students grasped the basic concepts of the materials and listed some very good examples, including the legs on their desks (metals), windows (ceramics), and plastic toys and pencil cases (polymers).

After the basic introduction, I asked for assistants to experiment with materials. The hands went up again. The first experiment was intended to demonstrate the effect of cold temperatures on the properties of materials, specifically the toughness. I had a piece of tin rod, some plastic tubing, and an elastic band. Before starting, I had the students identify the materials. (I explained safety considerations, and volunteers had to wear safety glasses for their own protection as well as for effect. In the future I would like to add child-sized lab coats.) My first assistant demonstrated his strength to the class by bending the tin rod. I then asked him to try to break the rod with a hammer. He tried and tried, but the best he could do was to deform the rod. This, of course, clearly demonstrated the toughness of a metal at room temperature. Another volunteer did the same with the plastic tubing. The tubing was very flexible and could not be broken with a hammer. I then produced a dewar of liquid nitrogen (children just love liquid nitrogen), which I explained was a very cold liquid, about $200^{\circ} \mathrm{C}$ below zero, that looked just like water. To give them some perspective as to how cold $-200^{\circ} \mathrm{C}$ is, I told them that a very cold winter day in Edmonton was $30^{\circ} \mathrm{C}$ below zero. My assistants placed the plastic tubing and tin into the liquid nitrogen. The plastic was removed with tongs and hit with a hammer, whereupon it shattered into many pieces. The same was done for the tin, which broke into a few pieces. The materials were covered with a cloth before being hammered to prevent broken material from flying about. I emphasized to the class that many materials that are tough at room temperature may not be very tough at lower temperatures. I mentioned a garden hose (a polymer) as an example. It is very flexible when used in the summer, but becomes very brittle and may crack if left outside during the winter. I also gave other more important engineering examples. I stressed that one important part of the job of a materials engineer or scientist is to design and make materials that have the required properties for all possible conditions. As a final point, I showed that the plastic tubing regains its flexibility when warmed back to room temperature. The experiment was repeated with another volunteer using the elastic band.

The second experiment involved the use of a wire made from memory metal (Ni-Ti alloy). I explained that some metals were able to effectively remember their shapes, so that if deformed the metal could be returned to its original shape by heating. The wire I had was coiled up like a spring, which I straightened out. I gave another assistant the wire and a hair dryer. She was instructed to hold the wire by one end and direct the hair dryer at the wire. The students were amazed to 